\title{
Preparation and In vitro Evaluation of Orally Disintegrating Tablets (ODTs) of Alprazolam
}

\author{
Nusrat Islam Chaity ${ }^{1}$, Sabrina Rahman Archie $^{2}$ and Nusrat Ahmed ${ }^{2}$ \\ ${ }^{1}$ Department of Pharmacy, University of Dhaka, Dhaka-1000, Bangladesh \\ ${ }^{2}$ Department of Pharmaceutical Technology, Faculty of Pharmacy, University of Dhaka \\ Dhaka-1000, Bangladesh
}

(Received: September 03, 2018; Accepted: February 20, 2019; Published (Web): April 01, 2019)

Orally disintegrating tablets (ODTs) are different from other conventional oral tablets in terms of rapid disintegration of the tablet on the tongue rather than swallowing. This is convenient and advantageous for the patients who face difficulties in swallowing for instance, pediatric, geriatric, bedridden, physically and mentally retarded, psychiatric patents. Moreover, fast disintegration of orally disintegrating tablets leads to faster dissolution and absorption, producing rapid onset of action. ${ }^{1-3}$

Alprazolam is short acting banzodiazepine anxiolytic which is used in the treatment of anxiety and panic disorder. ${ }^{4}$ It is rapidly absorbed after oral administration having the onset of action in 0.7 to 1.8 hours with absolute bioavailability of 80 to $100 \%$. The elimination half-life is 9 to 16 hours and $80 \%$ of drug binds to serum protein, mainly albumin. ${ }^{5}$

Alprazolam conventional oral tablets are available in $0.25 \mathrm{mg}$ and $0.5 \mathrm{mg}$ tablet in Bangladesh. However no orally disintegrating tablet is available in market of Bangladesh. Besides, alprazolam ODT is only available in USA as brand Niravam which is manufactured by SCHWARZ Pharma. ${ }^{6}$ Therefore, the aim of this present study is to formulate orally disintegrating tablet of alprazolam by using various concentrations of different superdisintegrants such as croscarmellose sodium, sodium starch glycolate and crospovidone to compare and evaluate their effects on various quality parameters of the tablets.

Correspondence to: Sabrina Rahman Archie Mobile: +8801768345747

E-mail: sabrina.archie@du.ac.bd; archie.2711@gmail.com

Dhaka Univ. J. Pharm. Sci. 18(1): 129-133, 2019 (June) DOI: https://doi.org/10.3329/dujps.v18i1.41430
To formulate alprazolam ODT, active pharmaceutical ingredient and other excipients were measured individually according to the proposed formulation shown in table 1 and blended in mortar and pestle for 10 minutes. Then the mixture was passed through a 40 number mesh size aperture and collected. Finally, the blend was compressed using rotary punch machine. Total nine batches of alprazolam ODT were prepared by direct compression method.

Pre-compression parameters of the formulation mixture such as angle of repose ${ }^{7,8}$, Carr's index and Hausner's ratio were evaluated for ensuring proper flow property of powder mix ${ }^{9}$. Prepared nine batches (A1-A3, B1-B3 and C1-C3) were evaluated by performing weight variation test, friability test, hardness test, measurement of diameter and thickness, wetting time, dispersion time, dissolution study and potency test.

Ten randomly selected tablets from each batch were weighed individually and all together by electric balance. The average weight and the percentage deviation of the tablets were then calculated. As per US Pharmacopoeia (USP), the acceptable limit of weight variation is $\pm 10 \%$ for tablet weight of less than or equal to $130 \mathrm{mg}{ }^{10,11}$ For hardness testing, three tablets from each batch were taken and placed vertically in a digital hardness tester. ${ }^{12}$ The machine was then pressed and the breaking point of the tablet was noted. Generally, the acceptable value of crushing strength for tablet is $2-3 \mathrm{~kg} / \mathrm{cm}^{2}$. For friability testing, three alprazolam tablets from each batch were weighed individually and then placed in a 
Roche friabilator at $25 \mathrm{rpm} / \mathrm{min}$ for 4 minutes. The final weight was calculated and $\%$ friability was measured. ${ }^{12,13}$ According to the specification, the $\%$ friability value must be less than or equal to $1 \%$.To measure diameter and thickness, three tablets were taken from each batch individually and measured by digital slide calipers and average diameter and thickness were calculated.

For wetting time calculation, a piece of tissue paper folded twice was kept in a petri dish of $5.7 \mathrm{~cm}$ inner diameter, containing $6 \mathrm{ml}$ of purified water. One tablet from each batch was placed on the tissue paper and allowed to wet completely. The time required for complete wetting of the tablet was then noted. ${ }^{12,14}$ Dispersion time was calculated by taking one tablet from each batch and kept individually in the center of a petri dish $(5.7 \mathrm{~cm}$ diameter) which was previously filled with $9 \mathrm{ml}$ of phosphate buffer solution simulating the $\mathrm{pH}$ of saliva. Then the time required for the tablet to completely disintegrate into fine particles was noted. ${ }^{12}$

Dissolution test was performed using USP typeII apparatus and $900 \mathrm{ml}$ of phosphate buffer (PH 6.8) as the dissolution medium. Three tablets from each batch were taken for this test and the dissolution apparatus was set at $50 \mathrm{rpm}$ and $37^{\circ} \mathrm{C} \pm 0.5^{\circ} \mathrm{C}$ for 40 minutes. Five $\mathrm{ml}$ of aliquots were periodically withdrawn and filtered. The sample volume was replaced with an equal volume of fresh dissolution medium. Then, $0.2 \mathrm{ml}$ of filtrate solution was taken and made $10 \mathrm{ml}$ for 50 times dilution by using phosphate buffer of $\mathrm{pH} 6$. Finally, the samples were analyzed spectrophotometrically at $260 \mathrm{~nm} \cdot{ }^{11,}{ }^{15}$ For potency testing, one tablet from each batch was taken and crushed with a mortar and pestle. The powder sample equivalent to $10 \mathrm{mg}$ of alprazolam was weighed and dissolved in suitable quantity of phosphate buffer ( $\mathrm{pH}$ 6.8). The volume was adjusted to $100 \mathrm{ml}$ with the phosphate buffer $(\mathrm{pH} 6.8)$. The drug content was analyzed using UV spectrophotometer at $260 \mathrm{~nm}^{10,16}$

The data obtained from angle of repose indicated excellent flow property of the powder bed of nine batches. Carr's index and Hausner ratio showed good flow property of the formulation, according to the specification ${ }^{17}$.

Weight variation, diameter and thickness test, hardness, friability test of all nine batches showed less deviation which clearly indicates batch uniformity meeting the specification of USP. The results of wetting time and dispersion time showed that all the batches are in the specification. Among the nine batches, batch $\mathrm{A} 3$ and $\mathrm{C} 2$ showed lowest wetting time (22 seconds) and A1 showed lowest dispersion time (2.18 minutes). The results of precompression and physicochemical parameters of nine batches are shown in table 2 .

Table 1. Formulation of alprazolam orodispersible tablet (all amounts taken in mg)

\begin{tabular}{|c|c|c|c|c|c|c|c|c|c|}
\hline Ingredients & A1 & A2 & $\mathrm{A} 3$ & B1 & B2 & B3 & $\mathrm{C} 1$ & $\mathrm{C} 2$ & $\mathrm{C} 3$ \\
\hline Alprazolam & 0.5 & 0.5 & 0.5 & 0.5 & 0.5 & 0.5 & 0.5 & 0.5 & 0.5 \\
\hline Cross-povidone & 5 & 3.13 & 6.25 & - & - & - & - & - & - \\
\hline Sodium starch glycolate & - & - & - & 5 & 3.75 & 8.75 & - & - & - \\
\hline Crosscarmellose sodium & - & - & - & - & - & - & 2.5 & 1.25 & 6.25 \\
\hline Microcrystalline cellulose & 80 & 80.94 & 79.38 & 80 & 80.63 & 78.13 & 81.25 & 81.88 & 79.38 \\
\hline Sodium saccharine & 2.5 & 2.5 & 2.5 & 2.5 & 2.5 & 2.5 & 2.5 & 2.5 & 2.5 \\
\hline Magnesium stearate & 1.25 & 1.25 & 1.25 & 1.25 & 1.25 & 1.25 & 1.25 & 1.25 & 1.25 \\
\hline Aerosil & 0.625 & 0.625 & 0.625 & 0.625 & 0.625 & 0.625 & 0.625 & 0.625 & 0.625 \\
\hline Mannitol & 28.88 & 29.81 & 28.25 & 28.88 & 29.5 & 27 & 30.13 & 30.75 & 28.25 \\
\hline Pre-gelatinized starch & 6.25 & 6.25 & 6.25 & 6.25 & 6.25 & 6.25 & 6.25 & 6.25 & 6.25 \\
\hline
\end{tabular}


Table 2. Pre-compression and physicochemical parameters of the prepared batches.

\begin{tabular}{|c|c|c|c|c|c|c|c|c|c|}
\hline Parameter & A1 & $\mathrm{A} 2$ & A3 & B1 & B2 & B3 & $\mathrm{C} 1$ & $\mathrm{C} 2$ & $\mathrm{C} 3$ \\
\hline \multicolumn{10}{|c|}{ Pre-compression parameters } \\
\hline Angle of repose $\left({ }^{0}\right)$ & 17.74 & 18.39 & 27 & 29.25 & 25.7 & 27.26 & 23.66 & 18.39 & 23.25 \\
\hline Carr's index $(\%)$ & 12.12 & 13.15 & 13.15 & 7.4 & 14.64 & 19.51 & 26.67 & 8.18 & 11.62 \\
\hline Hausner's ratio & 1.14 & 1.15 & 1.15 & 1.08 & 1.17 & 1.24 & 1.36 & 1.09 & 1.13 \\
\hline \multicolumn{10}{|c|}{ Physicochemical parameters } \\
\hline Weight variation & Pass & Pass & Pass & Pass & Pass & Pass & Pass & Pass & Pass \\
\hline Friability $(\%)$ & 0.26 & 0.08 & 0.26 & 0.27 & 0.41 & 0.14 & 0.13 & 0.1 & 0.52 \\
\hline Hardness $\left(\mathrm{kg} / \mathrm{cm}^{2}\right)$ & 2.92 & 2.63 & 3.67 & 5.39 & 4.17 & 4.86 & 2.71 & 2.27 & 3.41 \\
\hline Diameter (mm) & 7.057 & 7.073 & 7.057 & 7.07 & 7.05 & 7.09 & 7.043 & 7.097 & 7.083 \\
\hline Thickness (mm) & 3.32 & 3.23 & 3.44 & 3.18 & 3.29 & 3.68 & 3.27 & 3.55 & 3.42 \\
\hline Wetting time (sec) & 31 & 33 & 22 & 29 & 33 & 31 & 35 & 22 & 27 \\
\hline Dispersion time (min) & 2.18 & 3.5 & 2.44 & 3.45 & 3.29 & 3.35 & 2.45 & 2.34 & 3.1 \\
\hline
\end{tabular}

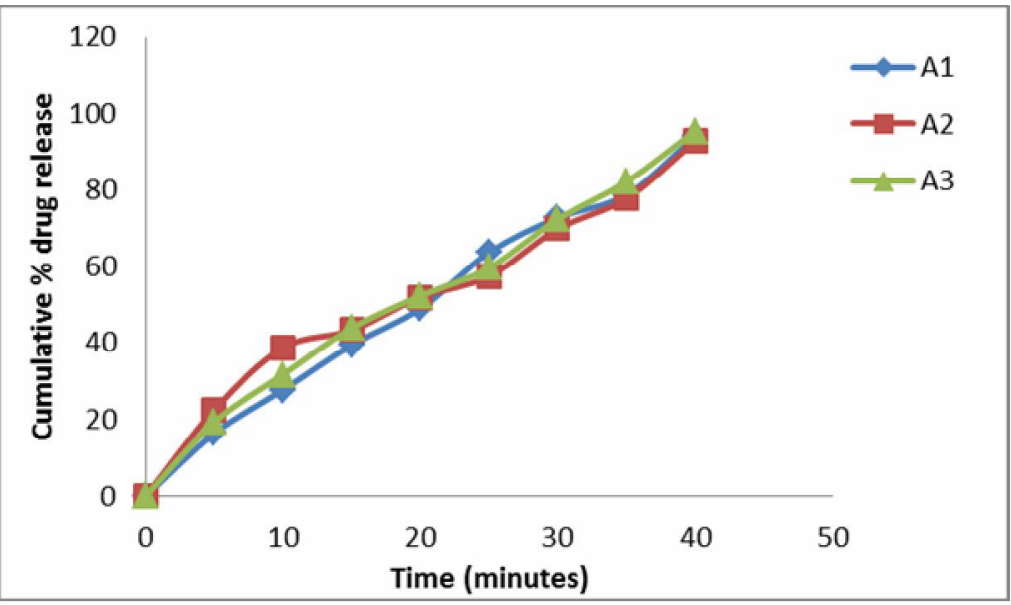

Figure 1. In vitro drug release profile of batch A1-A3.

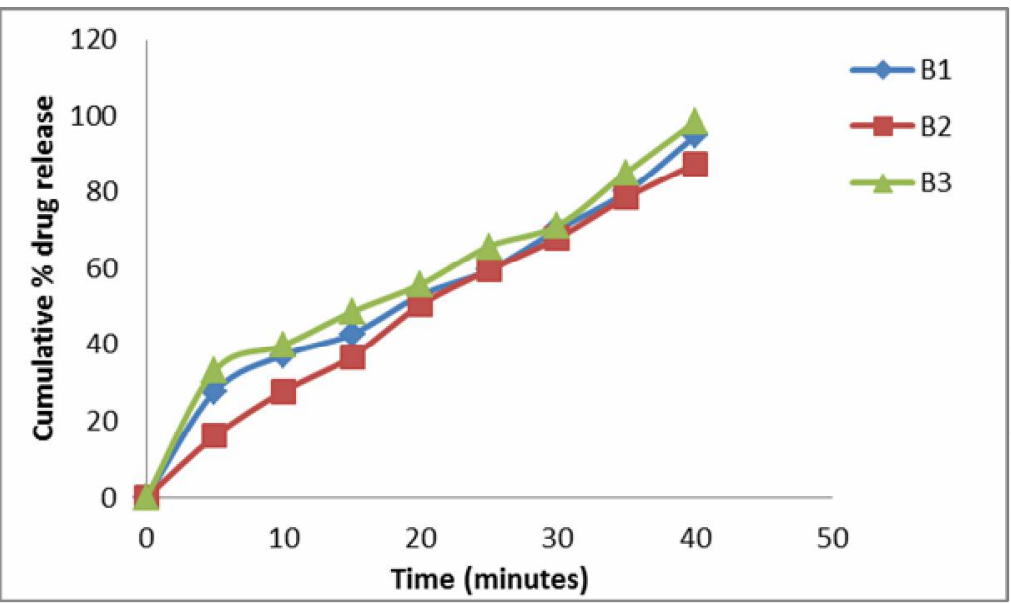

Figure 2. In vitro drug release profile of batch B1-B3. 


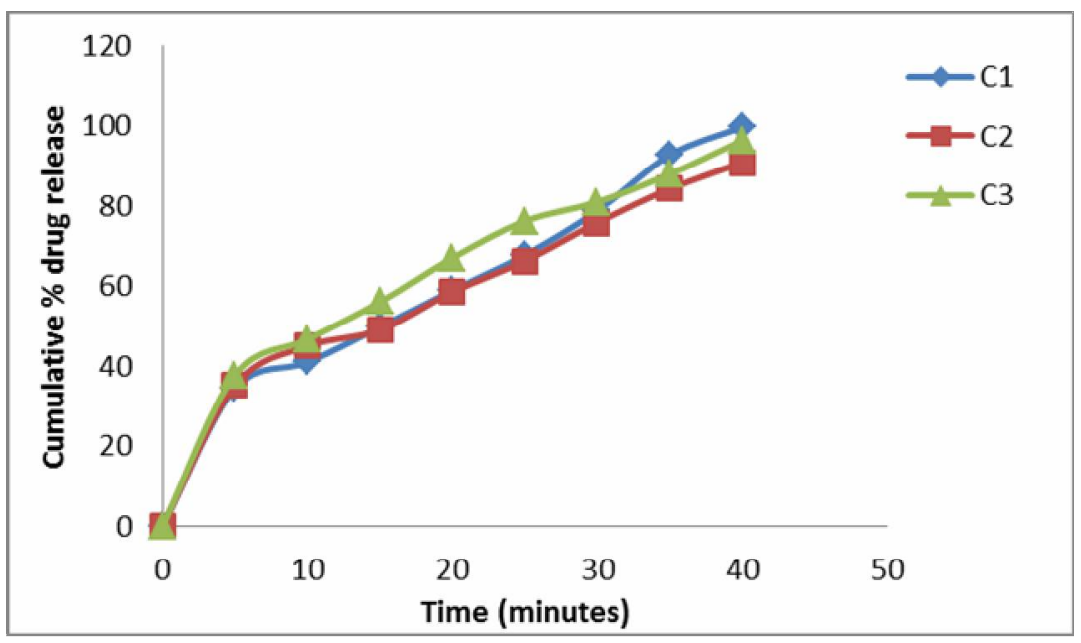

Figure 3. In vitro drug release profile of batch C1-C3.

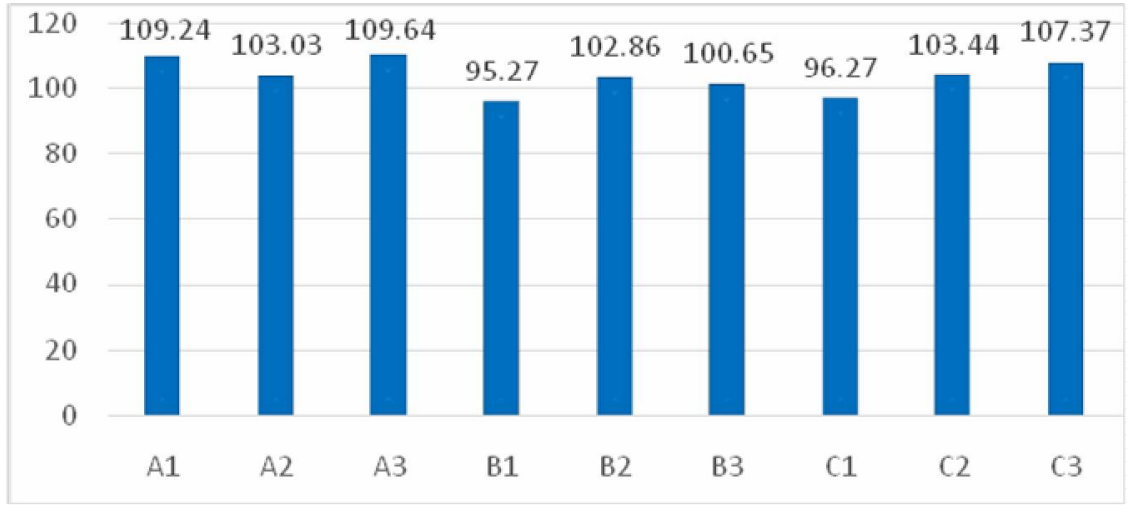

Figure 4. Potency (\%) of prepared formulations.

After performing dissolution study, it has been found that all the batches except B2 showed more than $90 \%$ of drug release in 40 minutes. Therefore, from the experiment it can be claimed that, croscarmellose sodium at 2.5, 4 and 5\% concentrations (range $0.5-5 \% \mathrm{w} / \mathrm{w}$ ), sodium starch glycolate at $3 \%, 4 \%$ and $7 \%$ concentrations (range 2$8 \% \mathrm{w} / \mathrm{w}$ ) and crospovidone at $1 \%, 2 \%$ and $5 \%$ (range $2-5 \% \mathrm{w} / \mathrm{w})$ concentrations can be used for formulating alprazolam orally disintegrating tablets. In vitro drug release profile of batches (A1-Ac, B1$\mathrm{B} 3$ and $\mathrm{C} 1-\mathrm{C} 3$ ) is shown in figures 1,2 and 3. Comparing the data obtainedform the dissolution study of nine batches, it is evident that Batch C1-C3 using crospovidone as superdisintegrant showed excellent percent drug release (34.39-99.61\%) in 40 minutes.

According to the specification, the acceptable potency range for drug potency is not less than $90 \%$ and not more than $110 \%$ for most low dose drugs. Figure 4 shows the result of the potency test and it has been found that all the batches met this specification (95.27 - 109.64\%) and batch A3 had the highest drug content.

The study of formulating and evaluating nine different batches of alprazolam orodispersible tablets using three different superdisintegrants draws a comparison among the batches on different quality 
parameters. It can be concluded that, among the nine batches, batch $\mathrm{C}$ shows satisfactory result as an orally disintegrating formulation of alprazolam using crospovidone as superdisintegrant.

\section{REFERNCE}

1. Roy, A. 2016. Orodispersible tablets: A review. Asian J. Pharm. Clin. Res. 9, 19-26.

2. Sharma, V., Singh, S.P., Nama, N. and Khinchi, M. P. 2017. Formulation and evaluation of orally disintegrating tablet of lamotrigine. Asian J. Pharm. Res. Dev. 5, 1-10.

3. S, V. and Vinushitha. 2010. Oral disintegrating tablets:An overview. Int. J. Chem. Pharmaceut. Sci. 1, 2.

4. Goldberg, R. 2009. Drugs across the spectrum. Cengage Learning, p.195.

5. Greenblatt DJ, Wright CE. 1993. Clinical pharmacokinetics of alprazolam. Therapeutic implications. Clin Pharmacokinet. 24, 453-471.

6. Alprazolam ODT-Web MD, accessed April8, 2018, https://www.webmd.com/drugs/2/drug-8171-510/alprazolamoral/alprazolamdisintegrating-tablet-oral/details

7. Shah, R.B., Tawakkul, M.A. and Khan, M.A. 2008. Comparative evaluation of flow for pharmaceutical powders and granules. AAPS PharmSciTech. 9, 250-258.

8. Remya, K.S., Beena, P., Bijesh, P.V. and Sheeba, A. 2010. Formulation development, evaluation and comparative study of effects of super disintegrants in cefixime oral disintegrating tablets. J. Young Pharm. 2, 234-239.

9. Pawar, H., Varkhade, C., Jadhav, P. and Mehra, K. 2014. Development and evaluation of orodispersible tablets using a natural polysaccharide isolated from Cassia tora seeds. Integ. Med. Res. 3, 91-98.
10. Dave, V., Yadav, R.B., Ahuja, R. and Yadav, S. 2017. Formulation design and optimization of novel fast dissolving tablet of chlorpheniramine maleate by using lyophilization techniques. Bull. Fac. Pharm, Cairo Univ. 55, 31-39.

11. Shah, S.J. and Mazumder, R. 2013. Formulation development and evaluation of mouth dissolving tablet of tramadol hydrochloride. Asian J. Pharm. Clin. Res. 6, 31-36.

12. Ibrahim, M.A., Sayeh, A.E. and Ela, A.E. 2017. Optimized furosemide taste masked orally disintegrating tablets. Saudi Pharm. J. 25, 1055-1062.

13. Türkmen, O., Şenyiğit, Z.A. and Baloğlu, E. 2018. Formulation and evaluation of fexofenadine hydrochloride orally disintegrating tablets for pediatric use. J. Drug Del. Sci. Tech. 43, 201-210.

14. Puttewar, T.Y., Kshirsagar, M.D., Chandewar, A.V. and Chikhale, R.V. 2010. Formulation and evaluation of orodispersible tablet of taste masked doxylamine succinate using ion exchange resin. J. King Saud Univ. (Sci.). 22, 229240 .

15. Ponugoti, R.S.R. and Gonugunta, C.R. 2014. Formulation and evaluation of mouth dissolving tablets of tramadol hydrochloride. Trop. J. Pharm. Res. 13, 669-675.

16. Wajid, S., Al-Arifi, M.N., Al Saleh, S.S., Babelgaith, S.D., Al Saleh, S.S. and Mohamed, A.R. 2015. Design and evaluation of orally disintegrating tramadol hydrochloride tablets by direct compression method. British J. Pharm. Res. 8, 1-8.

17. Lachman, L., Lieberman, H.A. and Kanig, J.L. 1987. The Theory And Practice Of Industrial Pharmacy. Lea \& Febiger, Philadelphia, p. 308. 